\title{
Sexualidades, Estatísticas e Normalidades - A persona numerabilis nos relatórios Kinsey, Masters \& Johnson e Hite*
}

\author{
Melissa Barbieri Oliveira** \\ Mara Coelho de Souza Lago***
}

Esse livro resulta da publicação da tese de doutorado do autor, Tito Sena, defendida no Programa de Pós Graduação Interdisciplinar em Ciências Humanas da Universidade Federal de Santa Catarina, em 2007. Cumpre destacar que a tese recebeu menção honrosa da CAPES na área interdisciplinar no ano de 2008.

Segundo as orientadoras Mara Lago e Miriam Grossi na apresentação do livro, Tito Sena, marcado pelo pensamento de Michel Foucault, fez em sua pesquisa uma verdadeira arqueologia do saber sobre sexualidade, buscando compreender a transformação desse saber no decorrer do século XX. Para tanto, procedeu à análise dos relatórios Kinsey, Masters \& Johnson $e$ Hite, publicados nos Estados Unidos entre os anos de 1948 e 1981 com os títulos: O Comportamento Sexual do Homem e O Comportamento Sexual da Mulher; A Resposta Sexual Humana e A Inadequação Sexual Humana; O Relatório Hite Sobre Sexualidade Feminina e O Relatório Hite Sobre Sexualidade

\footnotetext{
* Recebida para publicação em 11 de novembro de 2014, aceita em 29 de setembro de 2015. Resenha de SENA, Tito. Sexualidades, Estatísticas e Normalidades - A persona numerabilis nos relatórios Kinsey, Masters \& Johnson e Hite. Florianópolis, Ed. Mulheres, 2013.

** Doutoranda no Programa Interdisciplinar em Ciências Humanas da Universidade Federal de Santa Catarina (UFSC), área de Estudos de Gênero, Florianópolis, SC, Brasil. melissabarbieri@hotmail.com

${ }^{* * * *}$ Professora titular aposentada da UFSC, atuando como docente voluntária nos Programas de Pós-Graduação em Psicologia e Interdisciplinar em Ciências Humanas, da UFSC, Florianópolis, SC, Brasil. maralago7@gmail.com 
Masculina. O surgimento desses documentos foi significativo nos contextos sociais e históricos em que foram publicados, pois passaram a descrever comportamentos sexuais relatados por homens e mulheres, o que até então não era comum.

O livro é dividido em seis capítulos, além da introdução e da conclusão, e a partir do desenvolvimento da leitura pode-se perceber que a pesquisa realizada pelo autor não teve por objetivo analisar o conteúdo de cada um dos relatórios e suas estatísticas, mas sim o seu entorno, ou seja, a produção dos discursos que possibilitaram a emergência dos relatórios, tomados a partir de então como verdades científicas. Segundo o autor,esses discursos ajudaram a configurar um novo sujeito, que ele nomeia de persona numerabilis, ou seja, a pessoa que acaba por incorporar práticas consideradas normais de acordo com a média da população. Esse parece ser o mote do livro, mantido até as considerações finais.

Para chegar a essa conclusão, Sena utiliza-se de dois referenciais fundamentais, quais sejam: Georges Canguilhem e Michel Foucault. Do primeiro autor, foi fonte fundamental a obra $O$ normal e o Patológico. Quanto ao segundo, as obras As palavras e as coisas, das quais se extraíram conceitos chaves para instrumentalização da pesquisa e História da Sexualidade I, A vontade de saber, no que toca à busca da verdade através da confissão, trabalhada na obra.

Tito Sena identifica a influência de Canguilhem em Foucault no estudo das normatizações, e é nesse ponto que se estabelece a análise dos discursos sobre sexualidades presentes nos relatórios analisados, os quais revelam características comuns e peculiares. Destaca o fato de terem sido elaborados a partir de amostragem com indivíduos que respondiam enquetes e questionários; pelos/as autores/as dos relatórios serem pesquisadores/as norteamericano/as; por terem utilizado pesquisa estatística sistematizada e representativa; por serem traduzidos em várias línguas; pelos resultados de suas pesquisas terem sido popularizados no mundo todo; pelos relatórios serem considerados obras revolucionárias sobre a sexualidade; porque tiveram ressonância $e$ 
desdobramentos nas áreas de ciências biológicas, ciências da saúde e ciências humanas, bem como por terem sido alvos de muitas críticas e oposições.

Assim, o autor afirma que os relatórios se inserem na mesma lógica quantificadora que se instalou nos vários campos do conhecimento no século XX ou, numa terminologia foucaultiana, fazem parte de uma mesma configuração do saber, uma Epistéme, que ainda mantém uma Mathêsis, uma ordem e uma matemática confirmatória do conhecimento produzido.

No primeiro capítulo, denominado "O método $e$ a Interdisciplinaridade", Tito Sena apresenta os desafios da pesquisa interdisciplinar, trazendo a questão da complexidade das alternativas metodológicas possíveis em virtude das próprias particularidades das ciências humanas. Destaca também que os estudos de gênero e os estudos sobre sexualidade acabam sendo interdisciplinares por excelência, de forma que a intersecção das áreas disciplinares consideradas para o estudo foi imprescindivel para a análise dos documentos históricos utilizados. Partindo do ponto de vista foucaultiano a respeito das ciências humanas para mobilizar reflexões teóricas preliminares sobre os relatórios estudados, Sena busca as ferramentas arqueológico-discursivas como instrumento metolológico-analítico. Conclui assim que os relatórios Kinsey, Masters \& Johnson e Hite apresentam uma distinção da ordem de gênero, sexualidade feminina e sexualidade masculina, com naturalizações sendo reafirmadas ou positivadas, produzindo um tipo de homem e um tipo de mulher (p.49).

Quanto à arqueologia do saber, no caso da pesquisa desenvolvida, o autor informa que os focos difusos de poder foram os discursos científicos sobre sexualidade masculina $e$ feminina $e$ as relações de gênero (p. 50) e a partir dessas primeiras reflexões apresenta suas questões norteadoras, resumidas numa pergunta-chave: é a experiência do outro (ontem) que definirá a minha (hoje)? Para chegar às suas reflexões ancora-se no método arqueológico de Foucault, tomando como princípio básico que analisar discursos é descrever sistemas de dispersão num domínio 
de pluralidade articulatória, verificando que a análise arqueológica de discursos tem características interdisciplinares (p.52).

Tito Sena também explora a Genealogia do Poder, colocando que a genealogia trata do estudo das práticas sociais e, na visão de Foucault, é uma atividade de pesquisa meticulosa, que, no caso, pretende verificar como o corpo foi sendo objeto de produções, procurando descrever como as ligações entre verdade e poder emergiram e como se sustentam. Articulando Arqueologia do Saber com Genealogia do Poder, o autor busca analisar os discursos contidos nos relatórios sobre sexualidade privilegiando as categorias gênero e corpo, efetuando um mapeamento correlacional dos discursos, considerados referenciais das práticas.

No segundo capítulo, "Os Discursos e as Sexualidades Científicas", inicia suas considerações com os tópicos Verdade, Confissão e Ciência Sexual e A Norma e o Normal: Normatizar e Normalizar, nos quais comenta o uso polêmico da estatística nas ciências humanas. A partir das considerações esboçadas demonstra o disfarce de critérios quantitativos em critérios qualitativos $e$, por extensão, da prática discursiva comum de confundir descrições com apreciações, as quais são carregadas de julgamentos valorativos e normativos, fechando um círculo: "as frequências (estatísticas) definem as normalidades (axiológicas) e estas sustentam as frequências" (p. 81). Assim, pode-se perceber que tanto a normatização como formas de saber, quanto a normalização como forças do poder, são fixações enquadradoras de corpos, cujos processos se consolidaram no século XIX e prosseguiram no século XX. As construções realizadas por Canguilhem, Ewald, Foucault, Freud e Goffman, segundo Sena, demonstraram-se fundamentais para a articulação teórica da pesquisa, pois os discursos sobre sexualidade expressos através dos relatórios apoiados na lógica estatístico-matemática são dispositivos de quantificação e qualificação de práticas sexuais, constitutivos de uma medida de normalidade e anormalidade.

No terceiro tópico, A pesquisa, o Feminismo e os Estudos de Gênero, Tito Sena elabora uma síntese da evolução da categoria gênero, o papel do feminismo e os nexos com a perspectiva 
foucaultiana na elaboração desses conceitos. Destaca que para efetuar uma leitura foucaultiana da categoria gênero se faz necessário dar enfoque aos discursos sobre o masculino e o feminino, as assimetrias e desigualdades nos blocos de correlações de forças em oscilações de micro e macropoderes nas relações entre homens e mulheres. Por isso afirma que não há um discurso sobre gênero, mas discursos sobre gêneros (múltiplos), que revelam até mesmo contradições, ambiguidades e incertezas, pois são construídos histórica e culturalmente, estando em transformação contínua.

Além de Joan Scott, o capítulo se revela riquíssimo em virtude das autoras trabalhadas por Sena, que articula discursos de importantes teóricas do feminismo, como Simone de Beauvoir, Margareth Mead, Betty Friedan, Kate Millet, GermaineGreer, Shulamith Firestone, JullietMichell, ElizabehtRoudinesco, Judith Butler, Monique Wittig, Thomas Laqueur, Guacira Lopes Louro,Linda Nicholson, Elizabeth Grosz, Sandra Harding, MichèleBarret, RosiBraidotti, Miriam Grossi, Cláudia Lima Costa, Lia Zanota Machado. Encerra o tópico com Jane Flax, situando a amarração teórica entre a autora e Michel Foucault. Assim, conclui que a lógica binária é um operador do pensamento e é essa a lógica que sustenta os discursos triplamente atravessados por relações sociais de poder.

No terceiro capítulo, intitulado "Um Mapa Discursivo e Extradiscursivo", Tito Sena seleciona algumas continuidades $e$ rupturas do século XX, buscando mapear o entorno dos relatórios, tendo os discursos como acontecimentos do século XX. Para tanto, utilizou dez articulações possíveis de uma configuração interdiscursiva. Foram escolhidos a tecnologia, o cinema, a psicometria, as proibições sexuais, as políticas sanitárias, as mulheres, a demografia, a psiquiatria, a estatística (costura final entre os movimentos discursivos $e$ os movimentos extradiscursivos) finalizando com um panorama dos acontecimentos das décadas de 1950, 60 e 70.

$\mathrm{O}$ mais interessante dessa análise é que, sem os avanços tecnológicos que permearam o século $\mathrm{XX}$, os pesquisadores não 
poderiam chegar às conclusões apresentadas nos relatórios, pois tiveram à sua disposição recursos $e$ instrumentos que possibilitaram filmagens e gravações, o que era novidade na época. Também chama a atenção o item referente às leis $e$ proibições sexuais, que demonstram um cruzamento entre as esferas discursivas e extradiscursivas. Assim, vê-se que os discursos podem promover transformações mesmo em domínios aparentemente resistentes, nos limites do legal e ilegal e entre o normal e anormal. Da mesma forma no campo das políticas higienistas, no que toca às verbas de pesquisa institucional para a prevenção, educação e saúde pública. Com relação à Estatística e à Sexualidade, Sena destaca que Kinsey teve a ideia inovadora de aplicar a estatística em pesquisas da área da sexualidade, promovendo um debate com opiniões divergentes que produziram discursos que transformam comportamentos e comportamentos que transformam discursos.

Por fim, situa os contextos de publicação, as décadas de 50, 60 e 70, com o balizamento histórico dos acontecimentos sociais, políticos e econômicos. Merece destaque o poder de síntese do autor, que torna a leitura muito instigante pela forma de apresentar os fatos mais relevantes nos contextos pretendidos.

Nos três capítulos finais, são apresentados/descritos respectivamente os três relatórios, com um tópico final sobre o que se falou de cada um na época e no momento histórico em que foram lançados.

Sena apresenta Os Relatórios Kinsey mostrando não ser Alfred Charles Kinseyo único pesquisador envolvido no projeto, que contava com os colaboradores WardellBaxterPomeroy, psicólogo da prisão do Estado de Indiana, Clyde Martin, estatístico da Universidade de Indiana, e Paul Gebhard, antropólogo da Universidade de Harvard. Como a principal característica da pesquisa residia no fato de as informações serem trabalhadas estatisticamente, Kinsey tinha uma grande preocupação com a representatividade de sua amostra, já que entrevistou 11.240 indivíduos, e dedicou grande parte dos relatórios publicados para explicitar o histórico da coleta de dados e fontes, o método e a 
análise estatística. Além disso, Kinsey explicita no texto sua despreocupação com julgamentos de ordem moral, religiosa, cultural ou rotulações e categorias psiquiátricas. Os relatórios foram redigidos de forma seca e impessoal, abusando de gráficos e tabelas estatísticas. Porém Kinsey acreditava que o conhecimento verdadeiro dos fatores biológicos, psicológicos $e$ sociais das atividades sexuais era o caminho para o ajustamento entre natureza sexual do homem e exigências sociais (p. 178). Interessante notar que no relatório feminino, a linguagem muda, tendo ilustrações dos órgãos genitais femininos e masculinos e um estilo de texto mais fluente e didático (p. 182).

Outra curiosidade é o fato de os relatórios seguintes (M\&J e Hite) terem o intuito declarado de preenchimento de lacunas deixadas por Kinsey(p. 172), etambém a intenção de confirmarem alguns dos dados por ele apresentados (p.179). Esses relatórios, também foram tomados de certa forma como ferramentas para justificar as oposições aos padrões de normalidade e legalidade vigentes no meio norte-americano no pós-guerra. Ao final do capítulo, Sena apresenta os comentários sobre os relatórios de Master e Johnson e de Hite, que receberam as mais diversas críticas desde o meio acadêmico e científico, de profissionais clínicos, psicanalistas, médicos, psiquiatras, antropólogos, sociólogos até as instâncias religiosas, sendo de destacar as críticas de Simone de Beauvoir, Margaret Mead e Betty Friedan.

Em conclusão aos capítulos referentes ao conteúdo dos relatórios, Tito Sena aponta, na série de emergências discursivas e outras cadeias derivativas, a configuração depositária, geológica e arqueológica definida por Michel Foucault, ressaltando terem os discursos característica multiplicadora e reconhecimento histórico como acontecimentos (p. 199).

Tito Sena surpreende com suas reflexões finais, pois descobrimos que na verdade ele acaba por denunciar a existência de critérios normativos duvidosos de normalidades gerais $e$ normalidades específicas, tais como normalidades masculinas $e$ femininas, normalidades heterossexuais e homossexuais e o mais instigante, talvez: normalidades anormais $e$ anormalidades 
normais. Além disso, Tito Sena é muito honesto no registro de suas dificuldades e também provocativo, quando conclui que é a prática real da normalização que determina o conceito de normal, mas é com tal preocupação que lança a inquietante questão: $e$ quando um conceito é incorporado como preceito? E enfatiza que o uso do argumento da "maioria" para justificar o que alguém julga ser normal é um argumento estatístico que converte o comportamento da "maioria" em verdadeiro.

A pesquisa procurou problematizar a normalidade como critério objetivo e científico, o que é colocado em contraponto à normalidade como critério subjetivo. Assim, nas palavras do autor, as sexualidades descritivas são convertidas em prescritivas, tornando-se sexualidades normalizadas e verdadeiras e esse é o mecanismo estrutural e funcional que se revela através das estatísticas também utilizadas nas ciências humanas. 